\title{
A QUESTÃO DE GÊNERO, SEXUALIDADE E ORIENTAÇÃO SEXUAL NA ATUAL BASE NACIONAL COMUM CURRICULAR (BNCC) E O MOVIMENTO LGBTTQIS
}

\section{Paulo Roberto Souza Junior ${ }^{1}$}

\section{RESUMO}

$\mathrm{O}$ artigo enfoca a análise das questões de gênero, sexualidade e orientação sexual na atual BNCC - ou sua omissão - e as consequências diretas aos sujeitos do movimento LGBTTQIs. Até a edição da atual BNCC havia uma busca pela garantia de uma educação para diversidade. Entretanto, com a publicação da mesma, nasceu um retrocesso na temática. Há necessidade uma (re)avaliação do atual cenário político com finalidade de identificar os caminhos da participação da sociedade na busca da revisão deste retrocesso. Os resultados permitem concluir que há necessidade deste enfretamento para garantir a diversidade e o respeito às diferenças.

PALAVRAS-CHAVE: BNCC; Educação para diversidade; gênero, sexualidades e orientação sexual; LGBTTQIs; PCNs.

\section{THE ISSUE OF GENDER, SEXUALITY AND SEXUAL ORIENTATION IN THE CURRENT NATIONAL CURRICULAR COMMON GROUND (BNCC) AND THE LGBTTQIS MOVEMENT}

\begin{abstract}
The article focuses on the analysis of the issues of gender, sexuality and sexual orientation in the current BNCC - or its omission - and the direct consequences to the subjects of the LGBTTQIs movement. Until the issue of the current BNCC there was a quest to ensure diversity education. However, with the publication of the same, a setback was born in the theme. There is a need (re) evaluation of the current political scenario in order to identify the paths of society's participation in the search for a review of this retrocession. The results allow us to conclude that this struggle is necessary to guarantee diversity and respect for differences.
\end{abstract}

KEYWORDS: BNCC, Educantion for diversity; gender, sexuality and sexual orientation; LGBYYQIs; PCNs.

\section{1 - INTRODUÇÃO}

1 Possui graduação em Direito pela UGF (1991), Mestrado em Direito pela UNESA (2000). Atualmente, cursa disciplina isolada do Curso de Pós Graduação - Doutorado em Educação - ProPEd/UERJ, intitulada Tópicos Especiais: ESTÉTICA, CURRÍCULO E COTIDIANOS: ARTISAGENS E(M)

INTERSECCIONALIDADES. Pós Graduando em Gênero e Sexualidades pelas IES - FAVENI e UNYLEYA (2018). Professor - concursado, em Direito e Legislação, da FAETEC/RJ e da SEEDUC/RJ. E-mail: pauloroberto.coordenacao@gmail.com.br 
Este artigo traz como preocupação central a omissão da construção do gênero, sexualidade e orientação sexual dentro da Base Nacional Comum Curricular (BNCC), aprovada em 2017, devido a necessidade de preserva-se a identidade de gênero e o respeito a diversidade sexual entre os educandos. Trata-se da análise das desigualdades de gênero, dentro do ambiente escolar, e suas consequências ao movimento LGBTTQIs $^{2}$.

Desta forma, temos como hipótese a seguinte afirmação: que as construções sociais, no âmbito escolar, atribuídas ao movimento LGBTTQIs, ou seja, quais os papéis exercidos, na escola, pelo movimento, como sujeitos de direitos e obrigações, com finalidade de inclusão de seus membros, e, por conseguinte, a preservação dos mesmos nos bancos escolares.

Os sujeitos aqui mencionados definem as formas de viver e de ser, as quais devem ser contestadas para a garantia das identidades sexuais existentes, identifica-los, como homem ou mulher, traduz-se em nomeação de marcas distintivas de uma cultura, definindo, direitos e deveres, privilégios ou desvantagens a estes, pois todas as pessoas são sexuadas, ou seja, são seres dotados de sexualidade.

\footnotetext{
${ }^{2}$ Homossexualidade cuja orientação sexual e afetiva principal é uma pessoa do mesmo sexo anatômico. Esta orientação foi notada, inicialmente, na III Dinastia Egípcia, cerca de 2500 anos a.C. Entretanto, com o passar do tempo e a entrada das igrejas cristãs estas relações amorosas e sexuais passaram a ser consideradas como sodomia (atividade indesejável ou pecaminosa). O movimento de libertação homossexual, trouxe consigo inquietações feministas, sexuais, ecológicas e raciais que tramitam internacionalmente. Estão incluídos: lésbicas e gays.

Bissexualidade significa sentir atração sexual por ambos os sexos.

Travesti é uma pessoa que não se identifica com o gênero biológico e se comporta como pessoas de outro sexo (vestimenta, forma de agir, etc.).

Transexualismo quando a pessoa se identifica como sendo gênero oposto ao sexo refletido no corpo, como exemplo, mulher transexual possui gênero feminino, embora nascido com corpo masculino.

Queer se identificam como o sujeito da sexualidade desviante, onde problematizam as noções clássicas do sujeito e suas identidades usuais. Estes buscam analisar a multiplicidade de identidades sexuais e de gênero e, como, desconstruir as relações binárias, o que significa subverter, perturbar, entretanto, não significa destruir, já que visam a crítica entre o heterossexual e o homossexual. É considerado um termo guarda-chuva, onde todos os sujeitos que não se encontram confortáveis dentro do eixo masculino e feminino.

Intersexualidade é a ocorrência de qualquer variação de características sexuais, que dificultam a análise do sexo correto, pois nascem com genitálias ou características diferentes das dos padrões sexuais da sociedade e, por isso, não se trata de orientação sexual.
} 
Estes cruzam a fronteira do gênero e da sexualidade talvez não "escolham" livremente essa travessia, eles podem se ver movidos para tal por muitas razões, podem atribuir a esse deslocamento distintos significados (LOURO, 2016, p. 19). A natureza daquele "é ser, desde sempre, cultura" (BENTO, 2017, p. 89), não estando a ver com uma ou outra genitália, já que este se traduzem como o ponto basilar da análise dos desejos e das relações sexuais.

O gênero possui atributos performativos, a pratica do dia a dia e o reconhecimento dos papeis que o ser humano desenvolve em sociedade, ou seja, fazemos gênero todos os dias, onde seu papel inclui tudo o que uma pessoa diz ou faz para se revelar a si própria como possuidora de condição de moça/rapaz; homem/mulher, inclui a sexualidade, todavia, não se restringe a ela, pois esta é tida como sensações corpóreas e subjetivas emocionais da pessoa.

A identidade de gênero em conformidade com o gênero sexual que the atribuem ao nascer. Assim, se os fatores físicos nos trazem um corpo do homem (sexo biológico) e a pessoa sente-se como tal (identidade de gênero), nenhuma dificuldade teremos nessa análise. No entanto, se o sexo biológico apresentado e registrado no momento do nascimento não condiz com a identidade de gênero, estamos diante da transexualidade (SANCHES, 2015, 272) ou da pessoa travesti.

Sabemos que o primeiro contato com tal definição é no seio familiar, onde estes ao desejarem seus pais, buscam se moldar aos mesmos. Após tal momento, a escola se apresenta como interlocutora destes debates, os quais começaram a se intensificar nos anos de 70, onde buscavam a sua inserção nos currículos escolares, devido a mudança de comportamentos de jovens dos anos 60, mais tarde, tal debate se estrutura, devido a uma série de acontecimentos, como, o surgimento/fortalecimento de movimentos sociais feministas e LGBTs, que buscavam o respeito aos sujeitos envolvidos e o respeito a diversidade; a busca pela garantia dos direitos sexuais; a proliferação da epidemia do HIV-Aids.

Este debate fez o MEC ${ }^{3}$ incluir nos PCNs - Parâmetros Curriculares Nacionais, aprovados em 1997, a questão de gênero, como tema transversal, onde menciona que tal questão está inserida em praticamente todos os assuntos trabalhados pela escola, nas diferentes áreas, visando o respeito às diferenças.

\footnotetext{
${ }^{3}$ Ministério da Educação e Cultura
} 
O Plano Nacional da Educação foi instituído através da Lei 10. 172, de 09 de janeiro de 2001, que vigorou de 2001 a 2010, o gênero desaparece da apresentação geral do documento, mas aparece "timidamente" em alguns tópicos.

Em 2010, com a finalidade de eliminar o preconceito e discriminação à orientação e identidade de gênero foi encaminhado projeto de lei intitulado Plano Nacional de Educação para decênio de 2011-2020, onde previa a criação de uma rede de proteção do LGBT contra a exclusão destes. Este foi aprovado, em $2014^{4}$, sem a promoção do debate sobre a identidade de gênero e sexualidades nas escolas.

Seguindo esta linha conservadora, as bancadas religiosas conseguiram aprovar nos PNE locais, em 2015, a não inclusão dos referidos debates.

O (des)governo ou o "governo do golpe" de Michel Temer ao propor a Base Nacional Comum Curricular (BNCC), em sua versão final, deixou de fazer menção a tais questões, atendendo a pleito da referida bancada, pois a mesma defende que, o corpo deve ser educado para produzir e reproduzir o padrão normativo vigente. Os que desviarem da norma, serão alvo de constante escrutínio e poderão sofrer as sanções sociais inerentes. Esta versão foi entregue ao Conselho Nacional de Educação - CNE, em abril do ano mencionado, sendo aprovada no dia 22 de dezembro de 2017, através da Resolução CNE/CP $\mathrm{n}^{\mathrm{o}}$ 2, que institui e orienta a implantação da Base Nacional Comum Curricular.

Sem a presente discussão fica visível a possibilidade de violência de gênero e a discriminação sexual, no âmbito escolar, as quais podem se manifestar por meio de ameaças, agressões físicas, constrangimentos, assédio sexual e/ou moral e abusos sexuais e estupros. Não sendo outro entendimento de Guacira Louro: “...meninos e meninas aprendem, também desde muito cedo, piadas e gozações, apelidos e gestos para dirigirem àqueles e àquelas que não se ajustam aos padrões de gênero e de sexualidade admitidos na cultura em que vivem" (LOURO, 2003, p. 29).

A principal justificativa deste trabalho é o enfrentamento desta posição do (des)governo ou "governo do golpe", onde se pleiteia a revisão deste posicionamento e, por conseguinte, a realização de políticas setoriais que privilegiam a diversidade sexual e a inclusão dos sujeitos do movimento LGBTTQIs, dentro do contexto escolar.

A participação da sociedade civil organizada e dos educadores ligados à questão na busca do reconhecimento dos diferentes é mais uma etapa deste

\footnotetext{
${ }^{4}$ Lei 13.005/2014: Plano Nacional de Educação
} 
enfrentamento, onde pleiteia-se um arranjo na educação, voltada à educação para a diversidade com a eliminação do preconceito, discriminação e violência, especialmente no que se refere a questões de gênero e sexualidade. Essas questões requerem a adoção de políticas públicas educacionais capazes de debates sobre gênero, sexualidade, identidade de gênero e educação sexual garantindo a diversidade e o respeito às diferenças

Neste contexto, procuramos discutir as reproduções das desigualdades sexuais produzidas por pessoas heterossexuais a pessoas LGBTTQIs, em atos e normas, sobre gênero e sexualidades.

A pesquisa é justificada pelo fato de (re)avaliar a atuação do movimento LGBTTQIs na busca de uma educação voltada a diversidade e, por conseguinte, garantia da diversidade e eliminando o preconceito e a discriminação.

O instrumento utilizado dentro deste estudo será a pesquisa bibliográfica sobre a temática, onde serão apreciados estudos de artigos e os PCNs e BNCC na busca de condições para sintetizar uma análise correta e coerente desta política com finalidade de traçar os referidos caminhos para sua revisão. $O$ texto final foi fundamentado nas ideias e concepções de autores como, BENTO (2017), BUTLER (2017), LOURO (2016) e FOUCAULT (1999).

\section{2- Sexualidade, sexo e corpo}

Cada sociedade tem seu regime de verdade, sua "política geral" de verdade: isto é, os tipos de discursos que ela acolhe e faz funcionar como verdadeiros; os mecanismos e as instâncias que permitem distinguir os enunciados verdadeiros dos falsos, a maneira como se sanciona uns e outros; as técnicas e os procedimentos que são valorizados para a obtenção da verdade; o estatuto daqueles que têm o encargo de dizer o que funciona como verdadeiro (FOUCAULT, 2004, p.12), tais discursos são reproduzidos na sexualidade e no gênero, este será estudado no capítulo 03.

A sexualidade é tida como sensações corpóreas e subjetivas emocionais, onde sua primeira abordagem inicia-se entre os cinco e seis anos e dar-se-á dentro do espaço privado, ou seja, em casa, quando as diferenças são interiorizadas, levando a organização dos papeis sexuais e demonstrando o lado que a sua sexualidade é orientada, ou seja, homossexual, heterossexual ou bissexual. 
Esta é derivada de uma produção cultural, e, não somente oriunda de um processo biológico, sendo observada dentro dos seguintes contextos: subjetivo (questões emocionais e cognitivas); familiar (valores morais e religiosos); e, econômico (diferenças culturais e momentos históricos).

Diferentemente da sexualidade, o sexo está ligado a práticas sexuais, ou seja, a questões genitais, sendo dividido em feminino, masculino ou intersexual. É a expressão biológica que define um conjunto de características anatômicas e funcionais, ou seja, "é uma interpretação política e cultural do corpo, não existe a distinção sexo/gênero em linhas convencionais; o gênero é embutido no sexo, e o sexo mostra ter sido gênero desde o início" (BUTLER, 2017, p. 197).

Há uma restrição visualizada dentro das características de sexo que pressupõe este atender as características reprodutivas previstas, dentro da heterossexualidade, barreira que deverá ser retirada para a garantia de um sexo livre.

Nesta esteira, precisamos entender a função dos corpos na relação entre gênero e sexualidade, onde estes podem ser entendidos como possíveis mensageiros, produzidos na pluralidade de culturas e práticas educativas.

Falar do corpo é falar, também, de nossa identidade dada a centralidade que este adquiriu na cultura contemporânea cujos desdobramentos podem ser observados, por exemplo, no crescimento mercado de produtos e serviços relacionados ao corpo, a sua construção, aos seus cuidados, a sua libertação e, também, ao seu controle (GOELLNER, 2013, p. 31).

O corpo porta em si a marca da vida social nos mais diversos âmbitos, fazendo com que a sociedade imprima nele determinadas transformações. Se viermos a considerar todas as modelações que sofre, constataremos que o corpo é "pouco mais que uma massa de modelagem à qual a sociedade imprime formas segundo suas próprias disposições: formas nas quais a sociedade projeta a fisionomia de seu próprio espírito" (RODRIGUES, 1983, p. 62).

A cultura dita normas em relação ao corpo, às quais o indivíduo tenderá, à custa de castigos e recompensas, a se conformar, aceitar e aderir, assim, este é "uma construção social, cultural e histórica" (GOELLNER, 2013, p. 35) e, por fim, é considerado como "uma realidade biopolítica" (FOUCAULT, 1992, p. 77), já que, a partir deste, é produzida sua identidade, sua personalidade, virtudes e defeitos. 
O corpo deve ser educado para produzir e reproduzir o padrão normativo vigente. Os que desviarem da norma, serão alvo de constante escrutínio e sofrerão as sanções sociais inerentes.

Uma matriz heterossexual delimita os padrões a serem seguidos e, ao mesmo tempo, paradoxalmente, fornece a pauta para transgressões. É uma referência a ele que se fazem não apenas aos corpos que se conformam às regras de gênero e sexuais, mas também aos corpos que as subvertem (LOURO, 2016, p. 17).

No caso dos homossexuais, por exemplo, eles se tornam o foco de discursos homofóbicos que os desqualificam e deslegitimam em função de sua sexualidade desviante da heteronormatividade ${ }^{5}$. Esses discursos se fundam em ideais moralistas, religiosos, higienistas, etc., e são mobilizados a fim de dizer a verdade sobre eles.

\section{3- Gênero: conceito, histórico e a legislação brasileira}

O gênero, ao longo da vida, é constituído através de práticas sociais e das instituições a constituição de homens e mulheres, onde há a "cultura constrói e distingue corpos e sujeitos femininos, torna-se necessário admitir que isso se expressa pela articulação de gênero com outras 'marcas' sociais, tais como classe, raça/etnia, sexualidade, geração, religião, nacionalidade” (MEYER, 2013, p. 19). É importante salientar que, nós não nascemos mulheres, nós nos tornamos mulheres, o mesmo se pode dizer de homens (BEAUVOIR, 1980).

O debate sobre o gênero é marcado por um espaço de lutas de interesses múltiplos, ou seja, este debate significa transitar por um conjunto de fatores que definem os termos masculino e feminino, pois "a natureza do gênero é ser, desde sempre, cultura" (BENTO, 2017, p. 89), não estando a ver com uma ou outra genitália, pois está relacionado à performance, a pratica do dia a dia e ao reconhecimento dos papeis que o ser humano desenvolve em sociedade, ou seja, fazemos gênero todos os dias.

\section{1 - O gênero na história mundial: uma breve análise}

\footnotetext{
${ }^{5}$ Norma que regula e legitima a heterossexualidade.
} 
A relação binária do gênero é heteronormativa, onde se posiciona na bipolaridade, entre homem e mulher, esta apresentou problema ao longo da história mundial, qual seja, a desigualdade social entre estes, pois a sociedade era patriarcal, onde o homem dominava a mulher, definindo a estas só a função de cunho doméstico, fato "aliado a combinação de crenças e instituições de cada civilização em particular" (STEARNS, 2017, p. 27). No período pós-clássico esta desigualdade ficou mais forte e evidente, devido ao padrão observado nas sociedades agrícolas existentes.

Esta relação binária era acompanhada pelo aceite da relação homossexual ou bissexual entre os integrantes da alta classe social de algumas civilizações, como na Grécia e em Roma, onde os jovens garotos eram seus protegidos e amantes.

Nos séculos XVI e XVII esta relação entre homens foi proibida e castigada pelas ideias cristãs sobre sexualidade adequada; já, no século $\mathrm{XX}$, as imigrações aumentaram e impulsionaram um contato entre culturas, as quais influenciaram o conceito de gênero.

No final dos anos de 1970 a política gay e lésbica vislumbra o debate entre "permanecer" ou "assumir, ou seja, ficar ou sair do armário, já que esta passou a ser mais atuante, deixando de lado, a política que visava a libertação mediante a transformação do sistema, até então propagada. Esta presumia-se na defesa de um sujeito com limites e características próprias. Com a chegada da AIDS, intitulada de "câncer gay", trouxe inúmeros preconceitos e discriminações aos sujeitos do movimento em questão.

Em relação ao movimento feminista, merece destaque, Olympe de Gouges, revolucionária que defendia a igualdade de direitos entre homens e mulheres. Em 1791, lançou a "Declaração de Direitos da Mulher e da Cidadã" como resposta à exclusão das mulheres dos direitos previstos na Declaração de Direitos do Homem e do Cidadão, documento fundamental da Revolução Francesa, tendo sido condenada à guilhotina dois anos depois (PIMENTEL, 2017).

Este movimento é instituído em três ondas, a primeira se baseia na luta da mulher pelo direito ao voto, sendo iniciado com a Proclamação da República e se perpetuando até 1930. No início do século XX, as ações feministas começaram a se voltar para as condições da mulher fora do Ocidente, na China, por exemplo. As manifestações feministas nos anos de 1920 foram intensificaram a adoção de modelos feministas ocidentais (STEARNS, 2017, p. 215 e 217). 
A segunda onda se iniciou entre os anos de 60 e 70, o feminismo americano "foi despertado em parte pela influente escritora francesa Simone de Beauvoir e seu poderoso livro $O$ segundo sexo. (STEARNS, 2017, p. 215). A influência feminista, a partir de 1970, trouxe a baile um debate sobre a questão de gênero e sua interseccionalidade com outros marcadores sociais da diferença e da desigualdade, tais como classe, raça, etnia, geração, orientação sexual, identidade de gênero.

E, por fim, a terceira onda que se refere a década de 1990, onde "gênero e sexo passam a ser criticados como discursos normativos que conferem sustentação ao dispositivo binário de gênero, que por sua vez representa um mecanismo de hierarquização e de controle social" (LANS, 2015, p. 48). "O período consolida-se como um momento de ruptura do sistema binário de gênero: homem/mulher; masculino/feminino. Emerge a afirmação de novas identidades de gênero, e inclusive a ideia de desconstrução da identidade de gênero, colocando em seu lugar a ideia de fluidez e performances de gênero" (PIMENTEL, 2017).

Nesta esteira da nova ordem pós-colonial e pós-socialista do mundo e no contexto da sociedade de informação e da política neoliberal, há um questionamento radical do sistema binário de gênero, pois para o "projeto neoliberal tenha êxito, os estudantes não devem apenas aprender os conteúdos nas aulas, mas também, e sobretudo, apreender o modo 'correto' de viver em sociedade. O aluno deverá aprender o código dos sinais e atender automaticamente a cada um deles" (FOUCAULT, 1999, p. 140), sem a possibilidade de debates, já que não se privilegia um cidadão crítico.

A questão gênero não é aceita por religiosos fundamentalistas por considerá-la uma construção falsa, que negaria a verdade da diferença sexual e, ao criticarem, tal momento, produzem uma confusão sobre os termos ligados ao gênero e identificando um dado inexistente, a chamada "Ideologia de Gênero, ou melhor dizendo, a Ideologia da Ausência de Sexo, é uma crença segundo a qual os dois sexos - masculino e feminino - são considerados construções culturais e sociais [...]" (SOFOS, 2017). Na mesma linha, SCHNAKE (2017) afirma que a "ideologia de gênero" seria uma tentativa de afirmar "que não existe uma identidade biológica em relação à sexualidade. Quer dizer que o sujeito, quando nasce, não é homem nem mulher, não possui um sexo masculino ou feminino definido, pois, segundo os ideólogos do gênero, isto é uma construção social". 
Em 1998, o Papa João Paulo II estava preocupado com a questão sobre a influência do conceito de gênero sobre a "família tradicional", a "verdadeira feminilidade" ou a "verdadeira masculinidade" e, por isso, divulgou a encíclica (carta apostólica) intitulada "Sobre a dignidade e a vocação da mulher" (Mulieris dignitatem), onde lembrava a todos o papel da mulher para a maternidade e que suas funções eram diversas aos homens. Nesta mesma linha, e com maior crítica a teoria de gênero, em 2012, o Papa Bento XVI, proferiu seu discurso de Natal, assim se posicionando, "De acordo com esta filosofia, o sexo já não é considerado um elemento dado pela Natureza e que o ser humano deve aceitar e estabelecer um sentido pessoal para a sua vida. Em vez disso, o sexo é considerado pela Ideologia de Género como um papel social escolhido pelo indivíduo, enquanto que no passado, o sexo era escolhido para nós pela sociedade. A profunda falsidade desta teoria e a tentativa de uma revolução antropológica que ela contém, são óbvias.

As pessoas [que promovem a Ideologia de Género] colocam em causa a ideia segundo a qual têm uma natureza que lhes é dada pela identidade corporal que serve como um elemento definidor do ser humano. Elas negam a sua natureza e decidem que não é algo que lhes foi previamente dado, mas antes que é algo que elas próprias podem construir. (...) Quando a liberdade para sermos criativos se transforma em uma liberdade para nos criarmos a nós próprios, então é o próprio Criador que é necessariamente negado e, em última análise, o ser humano é despojado da sua dignidade enquanto criatura de Deus que tem a Sua imagem no âmago do seu ser. (...) A Ideologia de Género é uma moda muito negativa para a Humanidade, embora se disfarce com bons sentimentos e em nome de um alegado progresso, alegados direitos, ou em um alegado humanismo. Por isso, a Igreja Católica reafirma o seu assentimento em relação à dignidade e à beleza do casamento como uma expressão da aliança fiel e generosa entre uma mulher e um homem, e recusa e refuta as filosofias de género, porque a reciprocidade entre o homem e a mulher é a expressão da beleza da Natureza pretendida pelo Criador" (SOFOS, 2017).

No XV Congresso Mundial de Sexologia, ocorrido na China, em 1999, foi aprovada a Declaração dos Direitos Sexuais pela WAS (World Association for Sexology), levando-se em conta que os referidos direitos são de cunho personalíssimo.

\section{2- A questão de gênero no Brasil}

A Declaração dos Direitos Universal dos Direitos Humanos (ONU, 1948) inclui a liberdade sexual entre as liberdades de expressar sua sexualidade de forma saudável e livre de qualquer preconceito, bem como a liberdade de expressar sua 
vontade sexual, opinião, longe de qualquer preconceito ou discriminação, base do Texto Constitucional de 1988.

Apesar do referido Texto respeitar esta diversidade e o convívio privilegiando uma sociedade plural, trata a temática, timidamente, já que a expõe, somente, no título que trata sobre direitos e garantias fundamentais, ao mencionar a dignidade humana, direito inerente à pessoas ao bem-estar, livre de qualquer tipo de discriminação, direito à isonomia entre homens e mulheres, sexualidade, saúde e de necessidade de preservação contra doenças, que independe de sua orientação sexual.

Assim sendo, pode-se compreender no sistema jurídico brasileiro que é proibida constitucionalmente toda e qualquer discriminação e violência por motivo de gênero, seja na perspectiva histórica dos direitos das mulheres, seja na perspectiva da identidade de gênero (PIMENTEL, 2017).

Ressaltamos que, o Brasil privilegia o exercício da cidadania plena e irrefutável por parte do educando, já que é signatário do PIDESC (Pacto Internacional sobre Direitos Econômicos, Sociais e Culturais) e do Protocolo de São Salvador (Protocolo Adicional à Convenção Americana sobre Direitos Humanos em matéria de Direitos Econômicos, Sociais e Culturais).

Embora seja signatário de vasta legislação internacional, como mencionado, não vemos na prática políticas setoriais, por isso, há necessidade de implantação e implementação de políticas setoriais ligadas ao gênero e a sexualidades, as quais deverão "visar à realização de objetivos definidos, expressando a seleção de prioridades, a reserva de meios necessários à sua consecução o intervalo de tempo em que se espera o atingimento dos resultados" (BUCCI, 2002, p.29), ou seja, a eliminação do preconceito e da discriminação por orientação sexual.

Em atenção a estas questões, foi lançado, em 1996, o Programa Nacional dos Direitos Humanos, onde a Secretaria de Direitos Humanos da Previdência República passou a defender os direitos da população negra, de indígenas e de lésbicas, gays, bissexuais, travestis e transexuais.

O período de 2001 a 2010 foi marcado por inúmeras políticas setoriais lançadas pelo governo federal que versaram sobre a temática.

Outro documento promulgado pelo governo federal foi o Plano Nacional de Educacional (PNE), Lei 10.172/2001, neste o gênero só aparece em alguns tópicos, entretanto, não aborda-se e sexualidade, diversidade de orientação e identidade sexual. 
O governo de Luiz Inácio Lula da Silva, 2003-2011, foi o governo que mais incentivou a inclusão do movimento LGBTTQIs, em sociedade, como sujeitos de direitos, e, por conseguinte, no âmbito escolar, coibindo o preconceito a discriminação por sua opção sexual. Para tanto, criou a Secretaria de Educação Continuada, Alfabetização e Diversidade (SECAD), a qual passou a ser chamada de Secretaria de Educação Continuada, Alfabetização, Diversidade e Inclusão (SECADI).

Em 2004, instituiu o Programa "Brasil Sem Homofobia", fruto da mobilização do CNCD e da sociedade civil LGBT, que visa eliminar o possível ódio a gays, gays, bissexuais, travestis e transexuais e o Plano Nacional de Políticas de Mulheres (20042008), sua função era transformar a cultura educacional e escolar, para promover a educação para a diversidade.

Continuando nesta linha, em 2009, foi instituído o Plano Nacional de Promoção da Cidadania e de Direitos Humanos LGBT, resultante das propostas aprovadas na I Conferência Nacional LGBT; e, no ano seguinte, foi realizada a Conferência Nacional de Educação - CONAE, que inseriu a diversidade sexual como parte das políticas educacionais.

O Plano Nacional de Promoção da Cidadania e Direitos Humanos de Lésbicas, Gays, Bissexuais, Travestis e Transexuais, elaborado por Comissão Técnica Interministerial, reflete o esforço do Governo e da Sociedade Civil na busca de políticas públicas que consigam responder às necessidades, potencialidades e direitos da população envolvida, a partir de sua implementação, bem como do fortalecimento do Programa Brasil sem Homofobia, segundo informações coletadas no seu texto de apresentação (http://www.arco-iris.org.br/wp-content/uploads/2010/07/planolgbt.pdf, acesso em 20.03.2018).

Outro importante documento foi Política Nacional de Enfretamento a Violência contra mulher, onde "os rapazes e os homens estão mais expostos a violência no espaço público, garotas e mulheres sofrem mais violência no espaço privado" (Política Nacional de Enfretamento a Violência contra mulher, 2011, p. 11). Esta violência deve se "considerar a dimensão de gênero, ou seja a construção social, política e cultural da(s) masculinidade(s) e da(s) feminilidade(s)" (idem p. 20); já, a discriminação referese a atitudes que prejudiquem os sujeitos de determinados grupos sociais.

O governo da presidente Dilma Rousseff, em 2011, optou pelo veto ao kit antihomofobia, fato que deixou a sociedade estarrecida, pois o processo construtivo de 
políticas LGBT a partir da realização da Conferência Nacional de Gays, Lésbicas, Bissexuais, Travestis e Transexuais, no governo Luiz Inácio Lula da Silva, foi derrubado.

No mesmo ano, foi encaminhado o Projeto de Lei $\mathrm{n}^{\circ}$ 2010, que institui o Plano Nacional de Educação para decênio de 2011-2020, base da Conferencia Nacional de 2010 e 2014, este previa no item 3.9, a criação de uma rede de proteção do LGBT contra a exclusão do movimento, devido ao preconceito e discriminação à orientação e identidade de gênero, nos seguintes termos: 3.9) Implementar políticas de prevenção à evasão motivada por preconceito e discriminação à orientação sexual ou à identidade de gênero, criando rede de proteção contra formas associadas de exclusão.

Este Plano tramitou pelo Congresso Nacional sob o PL n ${ }^{\circ}$ 8035/2010 e transformado em Lei Ordinária 13005/2014 ${ }^{6}$, a qual possui dez diretrizes, entre as quais a III e X, onde mencionam: Art. $2^{\circ}$ São diretrizes do PNE: (...) II - superação das desigualdades educacionais, com ênfase na promoção da cidadania e na erradicação de todas as formas de discriminação; (...) X - promoção dos princípios do respeito aos direitos humanos, à diversidade e à sustentabilidade socioambiental.

O item 39 foi suprimido durante os debates pelo Congresso Nacional, a pedido da bancada fundamentalista ${ }^{7}$. Entretanto, estamos diante de um Estado laico, marcado pela separação entre Estado e religião, não há religião oficial, fato que não poderia acontecer, já que somos uma sociedade aberta, livre, diversa e plural, onde deve-se garantir as condições de igual liberdade religiosa e moral, havendo uma separação nítida entre o Estado contemporâneo e a religião.

Em contramão aos pilares dos direitos humanos, nasceu no Brasil, em 2004, um movimento intitulado Escola Sem Partido, a qual visa retirar da escola a possibilidade de ensinar além de conhecimento, valores e formas de agir em sociedade e, por isso, prevê a "neutralidade" dos professores sobre as temáticas que envolvem os valores e crenças individuais.

\footnotetext{
${ }^{6}$ Este aprova o Plano Nacional de Educação (PNE) e dá outras providências, com vigência por 10 (dez) anos, a contar da publicação desta Lei.

${ }^{7}$ No Brasil, há dois tipos de credos religiosos, o credo fundamentalista e tradicional e os credos contemporâneos ou progressistas, onde os primeiros só reconhecem como correto a relação binária e, por conseguinte, não aceitam os diferentes; já, os segundos aceitam os diferentes respeitando, assim, a diversidade e, por conseguinte, os direitos fundamentais humanos.
} 
Este movimento "expende-se através de memes, imagens acompanhadas de breves dizeres", através de "quatro elementos principais: primeiro, uma concepção de escolarização; segundo, uma desqualificação do professor; terceiro, estratégias discursivas fascistas; e, por último, a defesa do poder total dos pais sobre os filhos" (CIAVATTA; FRIGOTTO, 2017, p. 9), onde se apresenta através dois eixos em relação a Base Nacional Comum Curricular (BNCC), segundo Elizabeth Macedo: (...) quanto à instância competente para sua aprovação e quanto ao seu conteúdo, mais especificamente, aos objetivos da aprendizagem e ensino. Ao pôr em xeque a competência do Conselho Nacional de Educação (CNE) e do MEC para a definição da BNCC, o movimento tem sustentado que a organização do documento em torno de direitos de aprendizagem, preconizada pela lei que instituiu o PNE, é 'invasão de competências. Em prol da separação entre espaço público e privado, transferindo a educação para o espaço privado da família, a quem caberia toda a formação moral e ética das crianças' (...) O espaço público da escola é destinado ao aprendizado de conteúdos; contra o viés ideológico de esquerda que sustentaria o documento apresentado à consulta pública; contra a diversidade cultural nos currículos; e, contra a ideologia de gênero nos currículos (...) Esse conjunto de demandas conservadoras do ESP em relação ao 'conteúdo' da BNCC é bastante pontual e aponta menos para o que deve fazer parte do currículo do que para o que deve ser excluído, para que a escola possa 'atender a todos'. As exclusões citadas explicitamente se referem a demandas político-partidárias, raciais, de gênero e de sexualidade. O potencial dessas exclusões para deslocar as articulações sobre a BNCC é preocupante, na medida em que elas focam diretamente demandas de grupos minoritários — de raça, gênero e sexualidade — que, ainda timidamente, têm conquistado algum espaço (MACEDO, 2017, p. 517).

O referido movimento apresenta-se como "não ideologização", entretanto, não há neutralidade mencionada e, por conseguinte há retrocessão dos direitos conquistados, especialmente, com relação aos direitos humanos ferindo o art. 12 da Convenção Americana dos Direitos Humanos, o qual é utilizado pelo movimento para questionar tal debate, o artigo assim define a Liberdade de consciência e de religião, como: 1. Toda pessoa tem direito à liberdade de consciência e de religião. Esse direito implica a liberdade de conservar sua religião ou suas crenças, ou de mudar de religião ou de crenças, bem como a liberdade de professar e divulgar sua religião ou suas crenças, individual ou coletivamente, tanto em público como em privado. 2. Ninguém pode ser objeto de medidas restritivas que 
possam limitar sua liberdade de conservar sua religião ou suas crenças, ou de mudar de religião ou de crenças. 3. A liberdade de manifestar a própria religião e as próprias crenças está sujeita unicamente às limitações prescritas pela lei e que sejam necessárias para proteger a segurança, a ordem, a saúde ou a moral públicas ou os direitos ou liberdades das demais pessoas. 4. Os pais, e quando for o caso os tutores, têm direito a que seus filhos ou pupilos recebam a educação religiosa e moral que esteja acorde com suas próprias convicções.

Este movimento está ferindo os princípios fundamentais do Estado Democrático de Direito, cujo objetivo é a garantia de uma sociedade livre, justa e solidária. "A ESP instaura um clima de vigilância, suspeição e punição aos identificados que pregam 'doutrinação' ou 'desrespeito às convicções morais da família" (ALGEBAILE; FRIGOTTO, 2017, p. 70), não sendo outro o entendimento de Gaudêncio Frigotto (2017) salienta que um dos argumentos basilares deste movimento é a tese da "Liberdade de Ensinar", entretanto, o que se quer é ao contrário.

Inúmeros municípios, durante o ano de 2015, seguindo orientação do movimento ESP, aprovaram projeto de lei proibindo o debate sobre o gênero em suas escolas, o que fez, o Procurador-Geral da República, Rodrigo Janot Monteiro de Barros, propor arguição de descumprimento de preceito fundamental contra tais dispositivos legais, com pedido de liminar, como foi o caso do Município de Paranaguá (PR), que aprovou a Lei 3.468 de 23 de junho de 2015, que institui o plano municipal de educação e veda política de ensino com informações sobre gênero no município em seu art. $3^{\circ}, X$, parte final.

Esta ADPF recebeu o $\mathrm{n}^{\mathrm{o}}$ 461, sob relatoria do Min. Luís Roberto Barroso, o qual suspendeu os efeitos da lei referida Lei, com a seguinte tese:

Impedir a alusão aos termos gênero e orientação sexual na escola significa conferir invisibilidade a tais questões. Proibir que o assunto seja tratado no âmbito escolar significa valer-se do aparato sexual para impedir a exclusão social e, portanto, para perpetuar a discriminação. (...) Ainda que se viesse a admitir a possibilidade do exercício de competência suplementar na matéria, seu exercício [pelo município] jamais poderia ensejar a produção de norma antagônica às diretrizes constantes da Lei 9.341/1996.

Em 2015, foi aprovada pelo Congresso Nacional lei que tipifica assassinatos motivados por gênero como "feminicídio", entretanto, a bancada religiosa vem atuando contrário ao movimento LGBTTQIs, propondo projetos de lei que visam prejudicar os 
sujeitos integrantes do mesmo, tais como, a proibição da adoção conjunto de casais homoafetivos (PL 620/2015); a retirada das expressões gênero", "diversidade” ou “orientação sexual” do documento do CONAE -2014 (PDC 122/2015); contrário ao uso do nome social e o reconhecimento da identidade de gênero de pessoas travestis e transexuais no âmbito da administração pública (PDC 395/2016), entre outros. A justificativa é que o gênero é entendido como "ideologia de gênero" que se constitui em ameaça grave à família tradicional heteronormativa.

Encontra-se em trâmite no Congresso Nacional o anteprojeto Estatuto da Diversidade Sexual, elaborado pela Comissão Especial da Diversidade Sexual do Conselho Federal da OAB. Sua finalidade é que se evite a discriminação e marginalização das pessoas que não se enquadram no padrão heterossexual (dentre elas: transexuais, travestis, transgêneros e intersexuais).

\section{4- Gênero, identidade sexual e orientação sexual nos PCNs (Parâmetros} Curriculares Nacionais) e na Base Nacional Comum Curricular (BNCC) de 2017.

Os currículos, a escola e as disciplinas podem produzir desigualdades de gênero, sexo e raça, etc., incentivando, por conseguinte, o preconceito, a discriminação e o sexismo. 'É indispensável que reconheçamos que a escola não apenas reproduz ou reflete as concepções de gênero e sexualidade que circulam na sociedade, mas que ela própria produz" (LOURO, 1999, p. 80/81).

Para que se evite tal momento e se privilegie o respeito aos direitos humanos há necessidade da realização de políticas setoriais, as quais são tidas como um conjunto de medidas e decisões tomadas por todos aqueles obrigados pelo Direito a privilegiar o interesse público.

Ressalta-se que, o termo "política", no inglês, politics, faz referência às atividades políticas: o uso de procedimentos diversos que expressam relações de poder (ou seja, visam a influenciar o comportamento das pessoas) e se destinam a alcançar ou produzir uma solução pacífica de conflitos relacionados a decisões públicas.

Maria Paula Dallari Bucci propõe que as políticas públicas deverão 'visar à realização de objetivos definidos, expressando a seleção de prioridades, a reserva de meios necessários à sua consecução o intervalo de tempo em que se espera o atingimento dos resultados". (BUCCI, 2002, p.29). 
Dentro destas perspectivas nasceram os PCNs - Parâmetros Curriculares Nacionais sendo considerados um marco para a entrada dos estudos de gênero e sexualidade no espaço escolar, devido a necessidade da inclusão de uma agenda cultural, sua chegada deu-se através das vozes dos movimentos sociais (feministas, gays e lésbicas, negros, meio ambiente).

Foi exatamente através dos temas transversais, em especial "Orientação sexual", que aponta "reconhecer como construções culturais as características atribuídas ao masculino e ao feminino, posicionando se contra as discriminações a eles associadas" (BRASIL, 1998, p. 311), que foi possível rever tais posicionamentos.

Estes trouxeram consigo as preocupações com questões éticas relativas à igualdade de direitos, à dignidade do ser humano e à solidariedade e as questões de meio ambiente, saúde, sexualidades foram cristalizadas.

A questão de sexualidade é apresentada no vol 10, onde é dividida em três eixos temáticos: corpo: matriz da sexualidade; relações de gênero; e, prevenção às doenças sexualmente transmissíveis/AIDS.

Em 2016, a Base Nacional Curricular Comum começa a ser definida através de inúmeras agendas, as quais definiram o que e como os alunos irão aprender a cada ano, na educação básica.

Sua versão final foi revisada pelo MEC e encaminhada ao $\mathrm{CNE}^{8}$, no fim de novembro de 2017, sem a previsão de debates sobre dois tópicos: objetos de conhecimento "corpo, gênero e sexualidade nas tradições religiosas" e definia que, nesse eixo, as escolas deveriam "discutir as distintas concepções de gênero e sexualidade segundo diferentes tradições religiosas e filosofias de vida" (https://oglobo.globo.com/sociedade/educacao/cne-retira-genero-orientacao-sexual-dabase-curricular-22179063\#ixzz5AHLlGt00, acesso em 20.03.2018), seguindo o pleito da referida bancada religiosa e do movimento ESP.

Em nota, o MEC diz que o documento "preserva e garante como pressupostos o respeito, a abertura à pluralidade, a valorização da diversidade de indivíduos e grupos sociais, identidades, contra preconceito de origem, etnia, gênero, convicção religiosa ou de qualquer natureza e a promoção dos direitos humanos"

\footnotetext{
${ }^{8}$ Conselho Nacional da Educação.
} 
(http://agenciabrasil.ebc.com.br/educacao/noticia/2017-04/mec-retira-termo-orientacaosexual-da-versao-final-da-base-curricular, acesso em 20.03.2018).

Esta versão foi aprovada pelo $\mathrm{CNE}$, após audiências públicas regionais realizadas em Manaus, Recife, Florianópolis, São Paulo e Brasília, com caráter exclusivamente consultivo, através da Resolução $\mathrm{CNE} / \mathrm{CP} \mathrm{n}^{\circ} 2$, datada de dia 22 de dezembro de 2017, que institui e orienta a implantação da Base Nacional Comum Curricular a ser respeitada obrigatoriamente ao longo das etapas e respectivas modalidades no âmbito da Educação Básica.

\section{5- Conclusão}

A escola é um local de relações sociais e, neste local, há necessidade de ser debatida a educação sexual, a qual deverá discutir as marcas identitárias, atribuídas aos sujeitos que poderão ser mecanismos de exclusão, devido a discriminação e ao preconceito.

Dentro deste debate, é apresentado o gênero e a sexualidade; onde o primeiro é um conjunto de representações sociais, históricas e culturais, assim, não sendo determinados por estruturas biológicas e, por isso, não revelam a sexualidade do sujeito; e, a segunda, embora tenha fundamento num corpo biológico, dever ser observada como uma construção social.

As pessoas constroem a si mesmas como masculinas ou femininas, reivindicando um lugar na ordem do gênero, as vezes misturados ou contraditórios, onde podemos usar os termos: queer, afeminado, masculinizado ou transgênero.

$\mathrm{Na}$ ordem de gênero, a desigualdade e a opressão têm levado repetidamente a demandas por reformas, discuti-lo é transitar sobre um conjunto de definições do que é ser masculino ou feminino, dentro de um espaço de lutas marcado por interesses múltiplos, não tendo haver com o tipo de genitália que a pessoa possui.

O corpo traduz a identidade da pessoa, pois a imagem dele se reproduz, seus gestos, seus sentidos que nele se incorporam.

No período de 1988 a 2002 há um recorte histórico de implantação de políticas públicas na área educacional, sobretudo, nos campos gênero, raça e direitos humanos, em especial, os PCNs que trouxeram consigo a preocupação do MEC com os projetos de educação sexual, ao incluir no eixo transversal, três itens: corpo: matriz da 
sexualidade; relações de gênero; e, a prevenção às doenças sexualmente transmissíveis/AIDS.

Os debates mencionados sobre a sexualidade tiveram o efeito de aproximá-los a ideias de risco e de ameaça, devido aos problemas que a sociedade vinha apresentando, como o crescimento da epidemia do HIV/Aids, ao invés de proporcionar caminhos ao prazer e à vida.

Por outro lado, houve um retrocesso sobre a discursão sobre gênero e sexualidades, no PNE (2015) e na BNCC (2017 - $3^{\text {a }}$ versão), documentos que suprimiram tal debate, atendendo aos pedidos da bancada fundamentalista / tradicional presente no Congresso Nacional e do movimento ESP.

Como forma de enfrentamento destes fatos, há necessidade de debatermos em Congressos, Seminários e através de nosso engajamento na luta pela busca do reconhecimento como sujeitos dos integrantes do movimento LGBTTQIs, e, por conseguinte, o fortalecimento de políticas setoriais de gênero e sexualidades destinadas aos mesmos, no âmbito escolar.

Buscando, assim, a garantia dos direitos fundamentais humanos, ou seja, a garantia da diversidade e o respeito às diferenças e, por conseguinte, a não exclusão dos sujeitos do referido movimento dentro do processo educacional.

\section{REFERÊNCIAS BIBLIOGRAFICAS}

ALGEB AILE, Eveline. Escola sem Partido: o que é, como age, para que serve. In: FRIGOTTO, Gaudêncio (org.). Escola "sem” partido: esfinge que ameaça a educação e a sociedade brasileira. Rio de Janeiro: UERJ, LPP, 2017, pp 63-74.

BENTO, Berenice. As tecnologias que fazem os gêneros. In: VIII CONGRESSO IBEROAMERICANO DE CIÊNCIA, TECNOLOGIA E GÉNERO. Curitiba: UFPR, 2010.

Transviad@s: gênero, sexualidade e direitos humanos.

Salvador: EDUFBA, 2017.

BEAUVOIR, Simone. O segundo sexo, vol. 1 e 2. Rio de Janeiro: Nova Fronteira, 1980.

BRASIL. Constituição (1988). Constituição da República Federativa do Brasil. Brasília: Senado Federal, 1988.

Revista de Gênero, Sexualidade e Direito| e-ISSN: 2525-9849 | Salvador | v. 4 | n. 1 | p. 1 - 21 | Jan/Jun. 2018 
BUCCI, Maria Paula Dallari. Direito administrativo e políticas públicas. São Paulo: Saraiva, 2002.

BUTLER, Judith. Corpos que pesam. In: LOURO, Guacira Lopes. O corpo educado: pedagogias da sexualidade. Belo Horizonte: Autêntica, 1999, p.151-172.

FELIPE, Jane. Erotização dos corpos infantis. In: LOURO, Guacira Lopes, FELIPE, Jane, GOERLLNER, Silvana Vilodre (org). Corpo, gênero e sexualidade: um debate contemporâneo na educação. 9a ed. Petrópolis, RJ: Vozes, 2013, p. 54 a 66.

FOUCAULT, Michel. Arqueologia do saber. Rio de Janeiro: Forense Universitária, 1995.

História da sexualidade 2: o uso dos prazeres. Rio de Janeiro:

Graal, 1998.

Vigiar e punir: nascimento da prisão. 20 ed. Petrópolis:

Vozes, 1999.

FRIGOTTO, Gaudêncio. A gênese das teses da Escola sem Partido: esfinge e ovo de serpente que ameaçam a sociedade e a educação. In: FRIGOTTO, Gaudêncio (org.). Escola "sem" partido: esfinge que ameaça a educação e a sociedadebrasileira. Rio de Janeiro: UERJ, LPP, 2017, pp 17-34.

FURLANI, Jimena. Educação Sexual: possibilidade didáticas. In: LOURO, Guacira Lopes, FELIPE, Jane, GOERLLNER, Silvana Vilodre (org). Corpo, gênero e sexualidade: um debate contemporâneo na educação. $9^{\text {a }}$ ed. Petrópolis, RJ: Vozes, 2013, p. 67 a 82

GOELLNER, Silvana Vilodre. A produção cultural do corpo. In: LOURO, Guacira Lopes, LANZ, Letícia. $O$ corpo da roupa: a pessoa transgênera entre a transgressão e a conformidade com as normas de gênero. Uma introdução aos estudos transgêneros.

Curitiba: Transgente, 2015.

LOURO, Guacira Lopes. Sexualidade, gênero e educação. Uma perspectiva pós-estruturalista. $3^{\circ}$ ed. Petrópolis: Vozes, 1999.

Currículo, gênero e sexualidade - $O$ "normal", o "diferente" e o “excêntrico". In: LOURO, Guacira Lopes, FELIPE, Jane, GOERLLNER, Silvana Vilodre (org). Corpo, gênero e sexualidade: um debate contemporâneo na educação. $9^{\mathrm{a}}$ ed. Petrópolis, RJ: Vozes, 2013, p. 43 a 53.

Um corpo estranho- ensaio sobre sexualidade e teoria queer. $2^{\mathrm{a}}$ ed. $3^{\circ}$ reimp. Belo Horizonte: Autêntica, 2016. 
MACEDO, Elizabeth. As demandas conservadoras do movimento escola sem

partido e a base nacional curricular comum. Revista Educ. Soc., Campinas, v. 38, $\mathrm{n}^{\circ}$. 139, p.507-524, abr.-jun., 2017

MEYER, Dagmar Estermann. Gênero e educação: teoria e prática. In: LOURO, Guacira Lopes, FELIPE, Jane, GOERLLNER, Silvana Vilodre (org). Corpo, gênero e sexualidade: um debate contemporâneo na educação. 9a ed. Petrópolis, RJ: Vozes, 2013, p. 11 a 29.

OLIVEIRA, João Manuel de. Desobediência do gênero. Slavador/BA: Editora Devires, 2017.

PIOSEVAN, Flavia. Direitos Humanos e Direito Constitucional Internacional. 14. ed., rev e atual. São Paulo: Saraiva, 2013

SANCHES, Patrícia. A pessoa transgênera e a proteção do direito à identidade de gênero no nome e no sexo civil. In: FERRAZ, Carolina Valença e LEITE, Glauber Salomão (coord). Direito à Diversidade. São Paulo: Atlas, 2015, pp. 271 a 280.

STEARNS, Peter N. História das relações de gênero [trad. Mirna Pinsky], $2^{\mathrm{a}}$ ed. $4^{\mathrm{a}}$ reimpressão. São Paulo: Contexto, 2017.

\section{BIBLIOGRAFIA COMPLEMENTAR}

AMBRA, Pedro. Psicanálise e cultura: O gênero entre a lei e a norma. In: Estud. av. vol.31 no.91 São Paulo Sep./Dec. 2017. http://dx.doi.org/10.1590/s010340142017.3191017, acesso em 20.03.2018.

PIMENTEL, Sílvia. Gênero e direito. Enciclopédia jurídica da PUC-SP. Celso Fernandes Campilongo, Alvaro de Azevedo Gonzaga e André Luiz Freire (coords.). Tomo: Teoria Geral e Filosofia do Direito. Celso Fernandes Campilongo, Alvaro de Azevedo Gonzaga, André Luiz Freire (coord. de tomo). 1. ed. São Paulo: Pontifícia Universidade Católica de São Paulo, 2017. Disponível em:

https://enciclopediajuridica.pucsp.br/verbete/122/edicao-1/genero-e-direito, acesso em 20 mar 2018.

SCHNAKE, C. Ideologia de gênero, conheça seus perigos e alcances. Disponível em: 〈https://destrave.cancaonova.com/ideologia-de-genero-seus-perigos-e-alcances/> Acesso em: 20 ago. 2017. 